\title{
High performance sulfur-containing copolyesters from bio-sourced aromatic monomers
}

\author{
Lesly Dasilva Wandji Djouonkep ${ }^{10}$, Zhengzai Cheng ${ }^{1,2 *}{ }^{(\mathbb{D}}$, William Mawuko Kodjo Siegu ${ }^{1}$, \\ Xiong Jing ${ }^{1}$, Jun Chen ${ }^{1}$, Elvis Kwame Adom ${ }^{1}{ }^{\circledR}$, Abubakar Muaz ${ }^{10}$, Mario Gauthier ${ }^{3}$ \\ ${ }^{1}$ Research Institute of Fine Organic Chemicals \& Organic Materials at School of Chemistry and Chemical Engineering, \\ Wuhan University of Science and Technology, 430081 Wuhan, China \\ ${ }^{2}$ Coal Conversion and New Carbon Materials Hubei Key Laboratory, Wuhan University of Science and Technology, \\ 430081 Wuhan, China; \\ ${ }^{3}$ Department of Chemistry University of Waterloo 200 University Avenue West Waterloo, Ontario Canada, N2L 3G1
}

Received 8 July 2021; accepted in revised form 10 September 2021

\begin{abstract}
In this investigation, a series of novel random bio-based thiophene-aromatic copolyesters, including thiophene and phenyl units, were successfully prepared from dimethyl 2,5-thiophenedicarboxylate, dimethyl 2,5-dimethoxyterephthalate, and the aliphatic diols ethylene glycol, 1,3-propanediol, 1,4-butanediol, 1,6-hexanediol and 1,8-octanediol, via twostep melt polymerization as a facile and green semi-continuous process. Techniques used to monitor the polymerization process included Fourier transform infrared (FTIR) and proton nuclear magnetic resonance spectroscopy $\left({ }^{1} \mathrm{H}\right.$ NMR), gel permeation chromatography (GPC), differential scanning calorimetry, thermogravimetric analysis, and dynamic mechanical analysis. The copolymers had tunable $T_{\mathrm{g}}$ values ranging from $47-120^{\circ} \mathrm{C}$, while their $5 \%$ decomposition temperature $\left(T_{\mathrm{d}, 5 \%)}\right.$ under $\mathrm{N}_{2}$ varied from $405-370^{\circ} \mathrm{C}$. GPC analysis showed that the polyesters had weight-average molecular weights $\left(M_{\mathrm{w}}\right)$ of $41400-48500 \mathrm{~g} / \mathrm{mol}$ and polydispersity indices of $1.47-2.24$. A study of structure-property relations showed that the properties of these copolymers can be tailored by varying their composition. All the copolyesters exhibited high tensile strength (45-80 MPa) and toughness values (elongation at break of 200-540\%). After 28 weeks of incubation in humid soil, weight losses of up to $7.2 \%$ were observed. Considering their good mechanical properties, thermal stability and biodegradability, these renewable sulfur-containing copolyesters have great potential to replace petroleum-based commercial poly(ethylene terephthalate) in the food packaging industry, which is helpful to implement carbon neutrality and sustainable development in the polymer industry.
\end{abstract}

Keywords: biodegradable polymers, aromatic monomers, aliphatic diols, mechanical properties, melt transesterification

\section{Introduction}

In recent years, much effort in polymer research focused on the development of monomers from renewable bio-sourced raw materials. Environment-friendly platform chemicals derived from multiple biomass sources, at a low cost, with diverse structures and functional groups, have been used in the synthesis of new polyesters [1]. The substitution of fossil resources with molecules extracted from biomass represents one of the most important goals of Green chemistry. This replacement is associated with two main objectives: the usage of renewable sources instead of fossil ones, and the development of a low-carbon bio-economy, geared toward reducing waste and minimizing resource consumption [2]. For instance, it has been estimated that the replacement of $20 \%$ of the carbon content in the world's current poly(ethylene terephthalate) (PET) production ( $\sim 37.5$ billion tons) with bio-based resources could reduce $\mathrm{CO}_{2}$ emissions by $17 \mathrm{Mt}$ [3]. The increased interest in 
bio-based renewable materials is motivated primarily by the fact that they contribute to the efficient use of natural resources, which is a prerequisite for the development of a more sustainable and resilient economy [4]. Sustainable materials that are biodegradable, such as poly(ethylene 2,5-furandicarboxylate) $[5,6]$ poly(1,4-butylene 2,5-furandicarboxylate) $[7$, 8], poly(lactic acid) [9, 10], and poly(butylene 2,5thiophenedicarboxylate) $[11,12]$ thus have become 'hot' research topics.

While common petroleum-based thermoplastic materials such as polycarbonate, PET, and poly(butylene terephthalate) exhibit excellent thermal, mechanical and optical properties, their degradation behavior in the environment is generally very poor. Conversely, currently available bio-based polymers generally display poorer mechanical properties partly attributed to the lack of rigid aromatic units in their structure but have interesting degradability characteristics $[13,14]$. The poor mechanical properties of many biodegradable bio-based polyesters limit their commercial applications.

It was pointed out in a recent literature review that polyesters derived from 2,5-furandicarboxylic acid (FDCA) display properties similar to or better than their terephthalic acid (TPA) analogues, and that these properties can be tuned further through copolymerization [15] . 2,5-Thiophenedicarboxylic acid (TDCA), like FDCA, is a promising bio-based monomer with a chemical structure similar to TPA, and its copolymers should likewise display interesting properties $[16,17]$. Studies on main-chain thiophene-aromatic polymers, comprising thiophene and phenyl repeating units within their polymer backbone, have provided an improved understanding of structure-property relationships in these materials $[18,19]$. Some of these thiophene-aromatic polymers display liquid-crystalline melt behavior, but also limited solubility [20]. Wang and coworkers [21-24] also reported polyesters derived from TDCA and mesogenic moieties such as terephthalate, naphthalate or 1,4-cyclohexanedimethylene units, and found that the polyesters derived from TDCA had lower melting temperatures than their terephthalic acid-based analogues, but these materials nevertheless displayed good thermal and mechanical properties. Furthermore, TDCA-based polyesters such as poly(trimethylene 2,5-thiophenedicarboxylate-co-trimethylene terephthalate), poly(propylene naphthalate-co-propylene 2,5-thiophenedicarboxylate), poly (ethylene 2,5-thiophenedicarboxylate) and poly(butylene-co-1,4-cyclohexanedimethylene 2,5-thiophenedicarboxylate) were likewise reported to have good thermal stability and mechanical properties, and to display some degree of biodegradability in a natural environment. Unfortunately, most of these polyesters exhibited low processing temperatures (usually below $200^{\circ} \mathrm{C}$ ), low molecular weights and moduli, high fragility and crystallization were not observed in most cases due to destruction of chain regularity by the rigid co-monomers.

To combine good material properties with biodegradability in the current investigation, we synthesized thiophene-aromatic copolyesters from TDCA and dimethyl 2,5-dimethoxyterephthalate (a symmetrical disubstituted phenyl aromatic monomer) in equimolar ratios as rigid backbone components. These were combined with aliphatic diol monomers as spacers to control backbone flexibility, affecting properties such as the glass transition temperature and the tensile properties, and possibly favoring the formation of high molecular weight polymers. A copolymerization strategy was selected to facilitate tuning of the physical and mechanical properties of these materials, which can be difficult to control in bio-based homopolymers [25]. This approach yielded polyesters with high processing temperatures, high molecular weights, and mechanical properties comparable to commercial PET. These polyesters also displayed good biodegradability, allowing them to decompose in a natural environment after their life cycle is completed, due to the presence of $\mathrm{C}-\mathrm{S}$ bonds sensitive to relatively abundant strains of sulfur-loving bacteria and other microorganisms in the soil.

2,5-Thiophenedicarboxylic acid (TDCA) is a stable thiophene derivative that can be synthesized from sugars, a renewable resource, even though that monomer is currently derived from adipic acid and thionyl chloride [24] (Figure 1a). TDCA and terephthalic acid are similar in that they both contain conjugated ring structures. In the current investigation, TDCA was converted to dimethyl 2,5-thiophenedicarboxylate (DMTD, a more convenient monomer) by esterification with methanol and sulfuric acid. A derivative of bio-sourced succinic acid, dimethyl 1,4-cyclohexanedione-2,5-dicarboxylate (Figure 1b), can be converted to dimethyl 2,5-dihydroxyterephthalate (DMDHT) and methylated to yield the monomer dimethyl 2,5-dimethoxyterephthalate (DMDMT) [26]. The structures of DMTD and DMDMT were characterized by FTIR and ${ }^{1} \mathrm{H}$ NMR spectroscopy, 


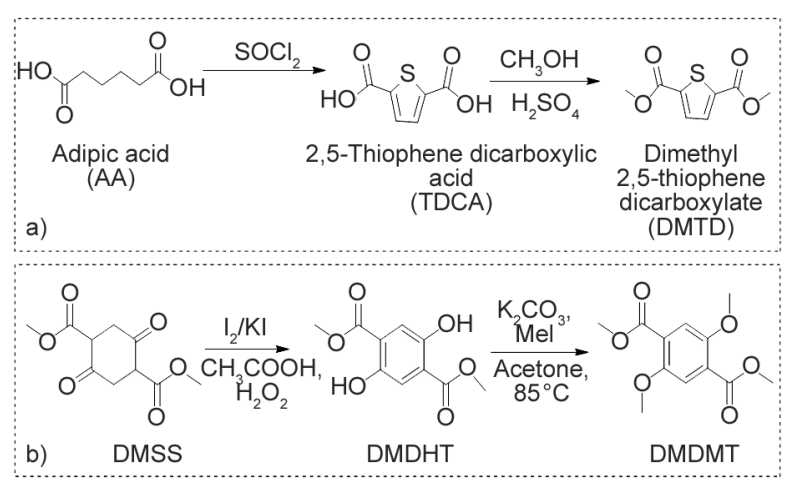

Figure 1. (a) Synthesis of dimethyl 2,5-thiophenedicarboxylate (DMTD) from adipic acid; (b) synthesis of dimethyl 2,5-dimethoxyterephthalate (DMDMT) from succinic acid.

and the monomers were reacted with aliphatic diols (Figure 1b) to obtain thiophene-aromatic copolyesters P1-P5.

We now report the synthesis and the characterization of these novel thiophene-aromatic copolyesters via a solvent-free method, from DMTD and DMDMT potentially derived from the biomass, in combination with aliphatic diols. The effects of varying the length of the diol spacer on the properties of the copolyesters were investigated to establish structure-property relations in these novel thiophene-aromatic copolyesters.

\section{Experimental procedures}

\subsection{Materials}

Dimethyl 2,5-thiophenedicarboxylate was obtained by esterification of 2,5-thiophenedicarboxylic acid (99\%, Lianyungang Yiqilai Chemical Co. Ltd., Jiangsu, China) with methanol and $\mathrm{H}_{2} \mathrm{SO}_{4}$, and DMDMT was synthesized as described below. Dimethyl 1,4-cyclohexanedione-2,5-dicarboxylate, ethylene glycol, 1,3-propanediol, 1,4-butanediol, 1,6-hexanediol, 1,8octanediol and antimony trioxide (all of analytical purity $>99 \%$ ) were purchased from the Aladdin Reagent Co. Ltd., Shanghai, China, methanol (99.9\%), $\mathrm{H}_{2} \mathrm{SO}_{4}(98 \%)$ and hydrogen peroxide solution $(30 \%$ $\mathrm{H}_{2} \mathrm{O}_{2}$ w/w) were from the Sinopharm Chemical Reagent Co. Ltd., Zhejiang, China, $\mathrm{KI}$ and $\mathrm{I}_{2}$ were from Tianjin Guangfu Technology Development Co. Ltd. (>9\%, Beijing, China), and chloroform $(\geq 99 \%)$ from Shangdong Hengchuang New Materials Co., Ltd. (Zhangqiu, China). All the chemicals were used as received without further purification.

\subsection{Characterization techniques and equipment}

Fourier transform infrared (FTIR) spectra were obtained on a Bruker Vertex 70 spectrometer from $4000-400 \mathrm{~cm}^{-1}$ at a resolution of $4 \mathrm{~cm}^{-1}$, by using $\mathrm{KBr}$ pellets and averaging five spectra. roton nuclear magnetic resonance $\left({ }^{1} \mathrm{H}\right.$ NMR) spectroscopy was performed on an AVANCE DMX600 instrument to monitor the composition and chemical structure of the copolyesters. All the samples were dissolved in $\mathrm{CDCl}_{3}$, with tetramethylsilane (TMS) as internal standard at room temperature $\left(25^{\circ} \mathrm{C}\right)$. Differential scanning calorimetry (DSC) and thermogravimetric analysis (TGA) measurements were performed on a Netzsch STA 449 F3 Jupiter instrument calibrated with indium. The DSC and TGA experiments were performed under $\mathrm{N}_{2}$ atmosphere from 0 to $300^{\circ} \mathrm{C}$ and 0 to $600^{\circ} \mathrm{C}$, respectively, at a heating rate of $10^{\circ} \mathrm{C} / \mathrm{min}$. The melting temperature $\left(T_{\mathrm{m}}\right)$ was determined from the second heating scan. Dynamic mechanical analysis (DMA) was carried out on a DMA Q800 Dynamic Mechanical Analyzer, at a frequency of $1 \mathrm{~Hz}$ and a ramping rate of $3^{\circ} \mathrm{C} / \mathrm{min}$. For sample preparation, $10.0 \mathrm{~g}$ of the polyester were compressed in a flat sheet vulcanizer at $230{ }^{\circ} \mathrm{C}$ for $5 \mathrm{~min}$ and cut into strips with $24 \mathrm{~mm}$ length, $5.6 \mathrm{~mm}$ width, and $1.18 \mathrm{~mm}$ thickness.

Tensile testing was achieved on a UTM6503 Electronic Universal Testing Machine (Shenzhen Sansi Material Testing Co., Shenzhen, China) at $23^{\circ} \mathrm{C}$, at an extension rate of $50 \mathrm{~mm} / \mathrm{min}$. The samples were prepared according to Chinese Standard GB528 2008 for type II dumbbells.

Polystyrene-equivalent molecular weights $\left(M_{\mathrm{n}}, M_{\mathrm{w}}\right)$ and polydispersity indices $\left(M_{\mathrm{w}} / M_{\mathrm{n}}\right)$ were determined by gel permeation chromatography (GPC) analysis on a Viscotek GPC Max instrument using THF $\left(25^{\circ} \mathrm{C}\right)$ or DMF $\left(40^{\circ} \mathrm{C}\right)$ as eluents, at a flow rate of $1.0 \mathrm{ml} / \mathrm{min}$. The system was calibrated with polystyrene standards.

The biodegradability of the polyesters was studied by the soil burial technique. The testing was conducted in an incubator with air and soil relative humidity levels maintained at 60 and $80 \%$, respectively. The temperature was maintained at $25-30^{\circ} \mathrm{C}$. The copolyester films, with a thickness of about $200 \mu \mathrm{m}$ and side lengths of $1 \times 1 \mathrm{~cm}^{2}$, were buried at $0.10 \mathrm{~m}$ in the soil. They were retrieved at predetermined 
times over a 28 week incubation period, when they were cleaned and dried at $50^{\circ} \mathrm{C}$ for $5 \mathrm{~h}$ in a vacuum oven. The extent of biodegradation was calculated using Equation (1):

Biodegradation $[\%]=\frac{W_{1}-W_{2}}{W_{2}} \cdot 100$

where $W_{1}$ and $W_{2}$ are the film weights before and after soil biodegradation, respectively.

\subsection{Synthesis of dimethyl}

\section{2,5-dimethoxyterephthalate}

Using dimethyl 1,4-cyclohexanedione-2,5-dicarboxylate as starting material, DMDMT was successfully prepared by a two-step synthesis. In the first step, the intermediate DMDHT was synthesized from the dione, followed by methylation of the phenol groups to produce dimethyl 2,5-dimethoxy terephthalate.

Dimethyl 1,4-cyclohexanedione-2,5-dicarboxylate $(13.7 \mathrm{~g}, 60.0 \mathrm{mmol})$ and glacial acetic acid $(<4 \mathrm{ml})$ were combined in a $250 \mathrm{ml}$ three-neck flask fitted with a reflux condenser and the mixture was heated to $80^{\circ} \mathrm{C}$ for $30 \mathrm{~min}$ under $\mathrm{N}_{2}$. Then $2.49 \mathrm{~g}(15 \mathrm{mmol})$ $\mathrm{KI}$ and $3.81 \mathrm{~g}(15 \mathrm{mmol}) \mathrm{I}_{2}$ were gradually added sequentially, followed by $10 \mathrm{ml}(0.10 \mathrm{~mol})$ of $\mathrm{H}_{2} \mathrm{O}_{2}$ solution dropwise, and the mixture was heated to reflux for $1 \mathrm{~h} .{ }^{1} \mathrm{H}$ NMR analysis revealed that $98 \%$ conversion was attained after that time. Upon cooling the flask in an ice bath, large amounts of brown crystals formed. The crude product was dissolved in a minimum amount of hot water and precipitated in methanol to give white needle-like crystals, that were filtered and vacuum-dried at $60^{\circ} \mathrm{C}$ for $3 \mathrm{~h}$ to give $11.5 \mathrm{~g}(51 \mathrm{mmol})$ of DMDHT in $85.1 \%$ yield.

DMDHT (9.05 g, $40 \mathrm{mmol})$ and $\mathrm{K}_{2} \mathrm{CO}_{3}(25.15 \mathrm{~g}$, $182 \mathrm{mmol}$ ) were dissolved in $320 \mathrm{ml}$ of acetone in a three-neck flask fitted with a reflux condenser. The mixture was heated to reflux for $30 \mathrm{~min}$ before $13.7 \mathrm{~g}$ (96 mmol) of $\mathrm{CH}_{3} \mathrm{I}$ was added drop-wise, and refluxing was continued for $8 \mathrm{~h}$. The mixture then was allowed to cool to ambient temperature and filtered. The solvent was removed on a rotary evaporator, and

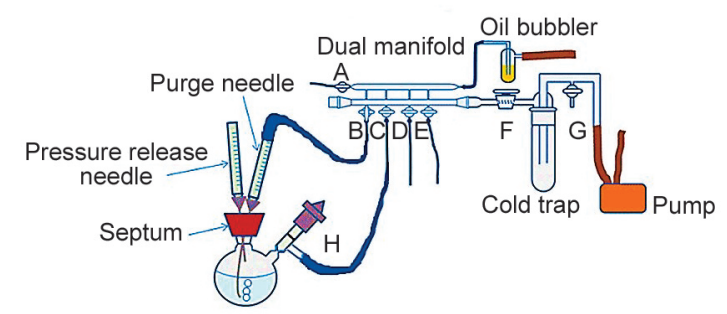

Figure 2. Synthesis setup. the solid product was washed with $10 \% \mathrm{~K}_{2} \mathrm{CO}_{3}$ solution, followed by distilled water three times. The purified product was finally dried under vacuum at $60^{\circ} \mathrm{C}$ for $3 \mathrm{~h}$ to give $8.13 \mathrm{~g}(32 \mathrm{mmol})$ of white DMDMT in $79.8 \%$ yield and $>98 \%$ purity. The controlled temperature setup used for the synthesis is shown in Figure 2.

\subsection{Synthesis of random copolyesters P1-P5}

For sample P1, dimethyl 2,5-thiophenedicarboxylate, dimethyl 2,5-dimethoxyterephthalate and ethylene glycol in a molar ratio of $0.5: 0.5: 1.1$, with $0.25 \mathrm{~mol} \%$ of antimony trioxide $\mathrm{Sb}_{2} \mathrm{O}_{3}$ catalyst (based on DMTD), were combined and the mixture was gradually heated to $140-160^{\circ} \mathrm{C}$ under $\mathrm{N}_{2}$ (esterification step). After $3-5 \mathrm{~h}$ the reaction mixture was transparent and methanol droplets formed in the attached condenser, confirming that the esterification reaction proceeded. Cycles of evacuation and $\mathrm{N}_{2}$ purging were repeated 5 times in the first step. The temperature was then increased slowly from 160 to $230^{\circ} \mathrm{C}$ over $4 \mathrm{~h}$ (polymerization step), and vacuum was applied slowly until the polyester became too viscous for stirring. The final product was a hard, sticky and whitish fiber-forming polymer. For polyesters P2-P5, 1,3-propanediol, 1,4-butanediol, 1,6hexanediol and 1,8-octanediol with varying diol molar ratios (1.3-1.5) and a set (0.5:0.5) diester ratio were used. The resulting polyesters were dissolved in chloroform, precipitated in methanol, and recovered by centrifugation. The product was rinsed by dispersion in $200 \mathrm{ml}$ of water-ethanol $(1: 1 \mathrm{v} / \mathrm{v})$, isolated by filtration, and dried for $4 \mathrm{~h}$ at $60^{\circ} \mathrm{C}$ in a vacuum oven. The esterification and polymerization temperatures yield, and appearance for each sample are provided in Table 1, while the synthetic procedure is summarized in Figure 3.

\section{Results and discussion}

The molar ratio of diesters was held constant at 0.5:0.5 in the reactions, but the diol:diester ratio was varied from 1.1-1.5 to ensure complete transesterification of the methyl ester groups of the monomers, and that the polymer chains were terminated with hydroxyl groups. Since DMTD can decompose at high temperatures, it was necessary to adjust the reaction conditions for different compositions to minimize thermal degradation. The random copolyesters were synthesized by melt transesterification polymerization using the monomer feed ratios, esterification and 
Table 1. Synthesis and characteristics of copolyesters.

\begin{tabular}{|ll|c|c|c|c|c|}
\hline \multicolumn{2}{|c|}{ Sample } & P1 & P2 & P3 & P4 & P5 \\
\hline Diester:Diol & & 1.1 & 1.3 & 1.5 & 1.4 & 1.3 \\
\hline Yield & {$[\%]$} & 89 & 87 & 83 & 82 & 90 \\
\hline Esterification temperature & {$\left[{ }^{\circ} \mathrm{C}\right]$} & 160 & 160 & 170 & 180 & 180 \\
\hline Polymerization temperature & {$\left[{ }^{\circ} \mathrm{C}\right]$} & 200 & 220 & 230 & 210 & 200 \\
\hline$M_{\mathrm{n}}$ & {$\left[10^{4} \mathrm{~g} / \mathrm{mol}\right]$} & 2.50 & 2.33 & 2.15 & 2.75 & 2.63 \\
\hline$M_{\mathrm{w}}$ & {$\left[10^{4} \mathrm{~g} / \mathrm{mol}\right]$} & 4.85 & 4.23 & 4.62 & 4.14 & 4.31 \\
\hline Polydispersity, $D$ & & 1.95 & 1.73 & 2.24 & 1.75 & 1.47 \\
\hline Appearance & & white & yellow & light yellow & light yellow & white \\
\hline
\end{tabular}

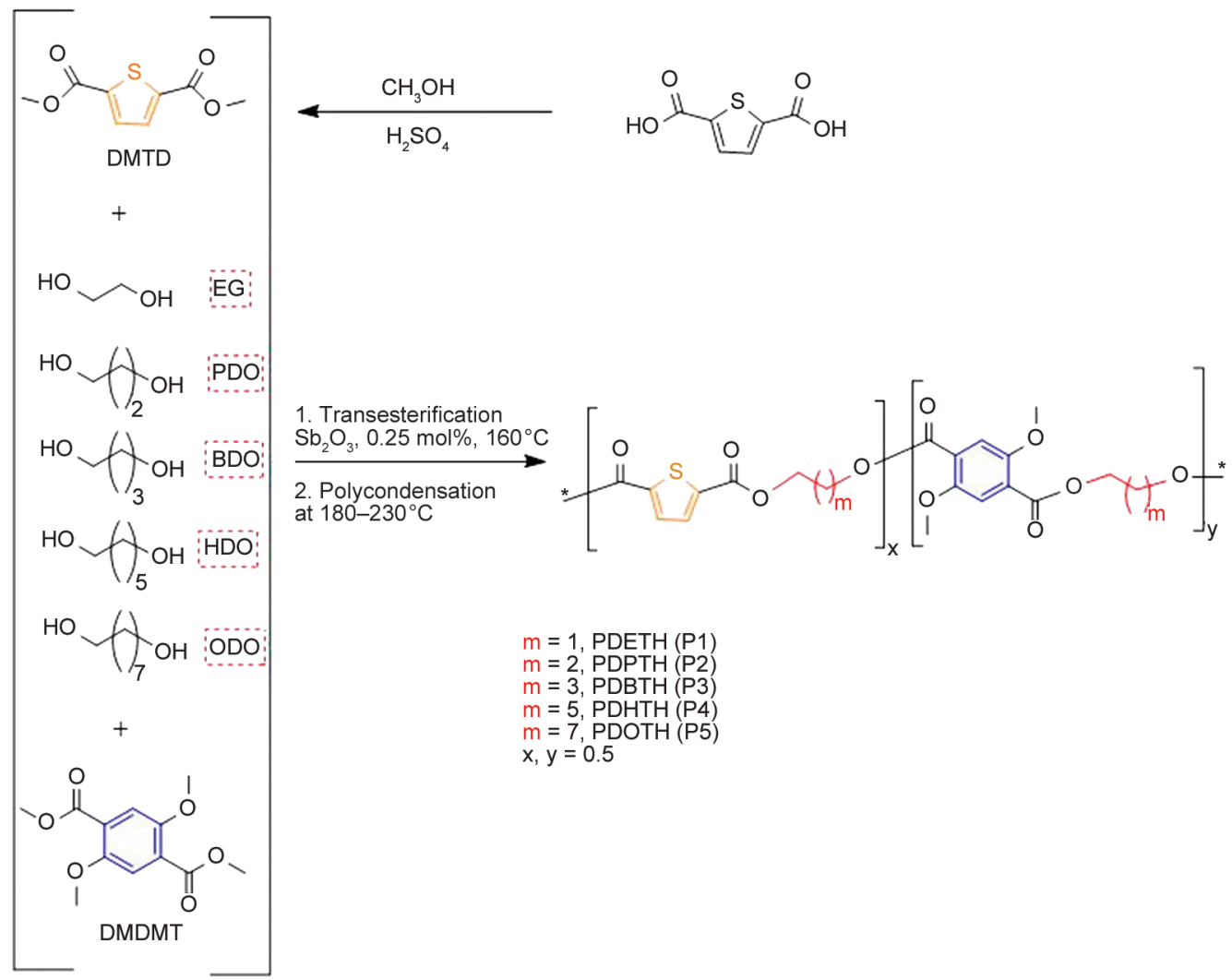

Figure 3. Synthesis route for copolyesters P1-P5; in spite of the representation used, the two types of repeating units are expected to be randomly distributed along the chains.

polymerization temperatures specified in Table 1. The coloration of the copolyesters, shown in Figure 4, varied from white to yellow. The incorporated monomer fractions at half conversion (determined by ${ }^{1} \mathrm{H}$ NMR spectroscopy), and the reactivity ratios

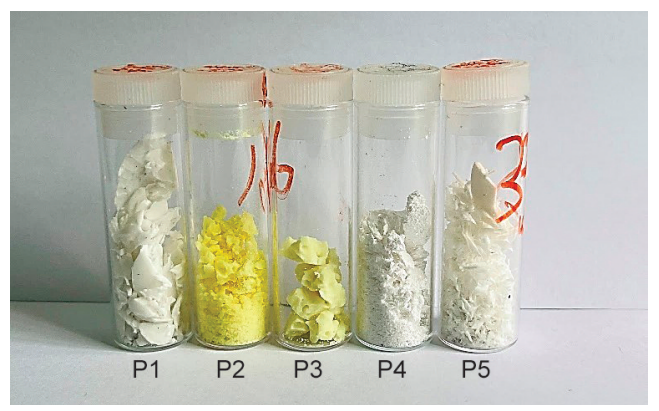

Figure 4. Appearance of copolyesters P1-P5. for the statistical copolymerization of DMTD and DMDMT indicated the formation of truly random copolymers [27].

\subsection{Fourier transform infrared (FTIR) and nuclear magnetic resonance (NMR) analyses}

The copolyesters $\mathrm{P} 1-\mathrm{P} 5$, prepared as $\mathrm{KBr}$ pellets for FTIR analysis, displayed different characteristic absorption bands (Figure 5). The $=\mathrm{CH}$ stretching peak, representative for the thiophene ring, appeared at $3120 \mathrm{~cm}^{-1}$. The asymmetric and symmetric $-\mathrm{CH}_{2}-$ stretching peaks were observed at 2927 and $2855 \mathrm{~cm}^{-1}$, respectively. All the spectra had characteristic ester absorptions, including a strong and 


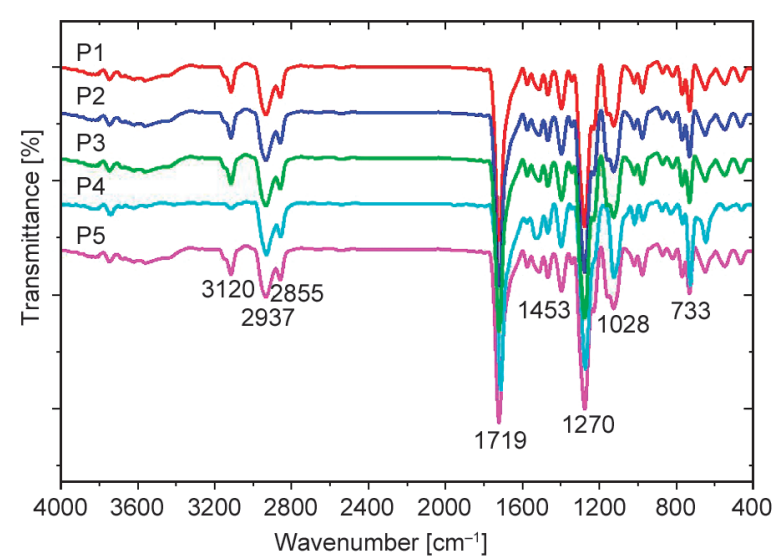

Figure 5. FTIR spectra of copolyesters P1-P5.

sharp $\mathrm{C}=\mathrm{O}$ stretching peak at $1720 \mathrm{~cm}^{-1}$, and two strong $\mathrm{C}-\mathrm{O}$ stretching absorptions in the regions of $1270 \mathrm{~cm}^{-1}\left(\mathrm{sp}^{2}\right.$ stretch) and $1050 \mathrm{~cm}^{-1}\left(\mathrm{sp}^{3}\right.$ stretch). The peak at $1453 \mathrm{~cm}^{-1}$ corresponds to an aromatic $\mathrm{C}=\mathrm{C}$ stretch, and the peaks at 1071 and $724 \mathrm{~cm}^{-1}$ is for 1,4-C-H bending, characteristic for DMDMT. The assigned peaks therefore confirm the presence of thiophene and phenyl units in the copolyesters chains.

The chemical structure of the copolyesters is shown in Figure 6, while the ${ }^{1} \mathrm{H}$ NMR spectra and characteristic signal assignments for the copolyesters are provided in Figure 7. The chemical shift for the $-\mathrm{CH}=$ absorption on the thiophene ring (signal a) is at 7.77-7.80 ppm, while for DMDMT it is at 7.55$7.62 \mathrm{ppm}$, and the $-\mathrm{CH}_{2}-(\mathbf{d}, \mathbf{e})$ connected to the ester bonds in $\mathrm{P} 1$ is at $4.66 \mathrm{ppm}$. All the $-\mathrm{CH}_{2}-(\mathbf{f}, \mathbf{h})$ units connected to the ester bonds in the different diols produced characteristic signals in the 4.30 4.33 ppm range. For $\mathrm{P} 2$, the signal for the $-\mathrm{CH}_{2}-(\mathrm{g})$ not connected to the ester bond appeared at $2.01 \mathrm{ppm}$, while for P3, (i) was at $1.79 \mathrm{ppm}$; for P4, (j) was at $1.45 \mathrm{ppm}$, and for P5, (k) was at $1.23 \mathrm{ppm}$. The peak at 3.88 ppm corresponds to the $-\mathrm{OCH}_{3}$ units (c). The chloroform $\left(\mathrm{CHCl}_{3}\right)$ peak appeared at $7.30 \mathrm{ppm}$, and the signal at $0 \mathrm{ppm}$ was for the tetramethylsilane (TMS) reference.

Analysis by ${ }^{13} \mathrm{C}$ NMR spectroscopy revealed carbon resonances corresponding to different functional groups in the copolyesters. ${ }^{13} \mathrm{C} \mathrm{NMR}[\mathrm{ppm}]\left(\mathrm{CDCl}_{3}\right)$, P1: 190, 162, 164 ( $\mathrm{C}=\mathrm{O}$ ester), 149, 143, 135, 134 (thiophene), 153, 164, 114, (phenyl), $55\left(\mathrm{O}-\mathrm{CH}_{3}\right)$, 63, $64\left(\mathrm{OCH}_{2}-\right)$; P2: 190.1, 162, $164.2(\mathrm{C}=\mathrm{O}$ ester $)$, 149.5, 134, 135, 143.1 (thiophene), 153, 127.6, 114.9, (phenyl), $55.5(\mathrm{O}-\mathrm{CH} 3), 70.8,61.1\left(\mathrm{OCH}_{2}-\right), 28.4$, 27.6 (aliphatic); P3: 190.3, 162, $164.2(\mathrm{C}=\mathrm{O}$ ester), 149.7, 143.1, 135, 134.8 (thiophene), 153, 164, 114, (phenyl), $55\left(\mathrm{O}-\mathrm{CH}_{3}\right), 63,64\left(\mathrm{OCH}_{2}-\right), 25.9,25.2$, 25.1 (aliphatic); P4: 190.1, 162, 164.2 ( $\mathrm{C}=\mathrm{O}$ ester), 149.5, 134, 135, 143.1 (thiophene), 153, 127.6, 114.9, (phenyl), $55.5\left(\mathrm{O}-\mathrm{CH}_{3}\right), 73,64.8\left(\mathrm{OCH}_{2}-\right), 31.7$, 29.5, 29, 25.5, (aliphatic); P5: 190.6, 162.5, 164.2 ( $\mathrm{C}=\mathrm{O}$ ester), 149.7, 134.5, 135.7, 143 (thiophene), 153.3, 127.6, 114.9, (phenyl), $55.5\left(\mathrm{O}-\mathrm{CH}_{3}\right), 73,64.8$ $\left(\mathrm{OCH}_{2}-\right), 31.7,29.7,29.6,29.3,25.8$ (aliphatic) All the signals assigned again confirm the synthesis of the

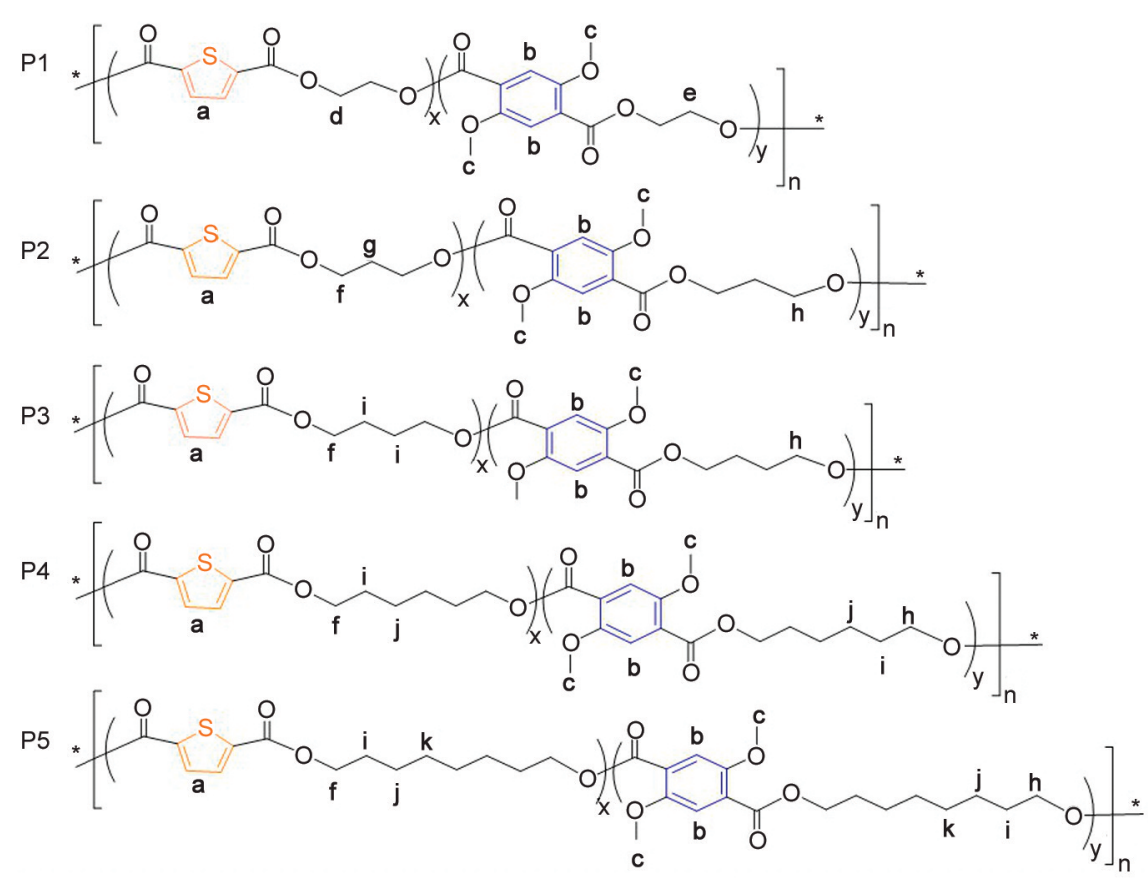

Figure 6. Chemical structure of the synthesized copolyesters P1-P5. 


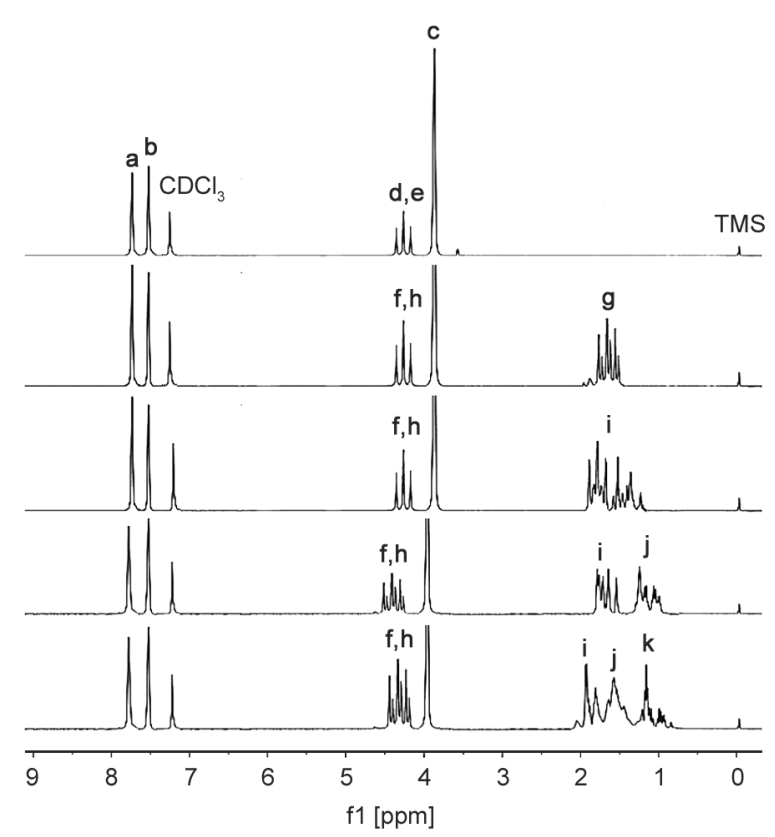

Figure 7. ${ }^{1} \mathrm{H}$ NMR analysis of copolyesters P1-P5.

target products. The observation of multiple signals for the $\mathrm{C}=\mathrm{O}$, and particularly the $\mathrm{OCH}_{2}-$ carbons, is consistent with the formation of random copolymer structures, as the chemical shifts of these carbon atoms would be sensitive to longer range inductive effects due to the presence of different types of ester linkages, derived from the TDCA and DMTD monomers, along the chain.

\subsection{GPC analysis}

To investigate structure-property relationships among the copolyesters, the molecular weight of the samples was measured by gel permeation chromatography (Figure 8), to ensure that the chains were sufficiently long for the properties to be molecular

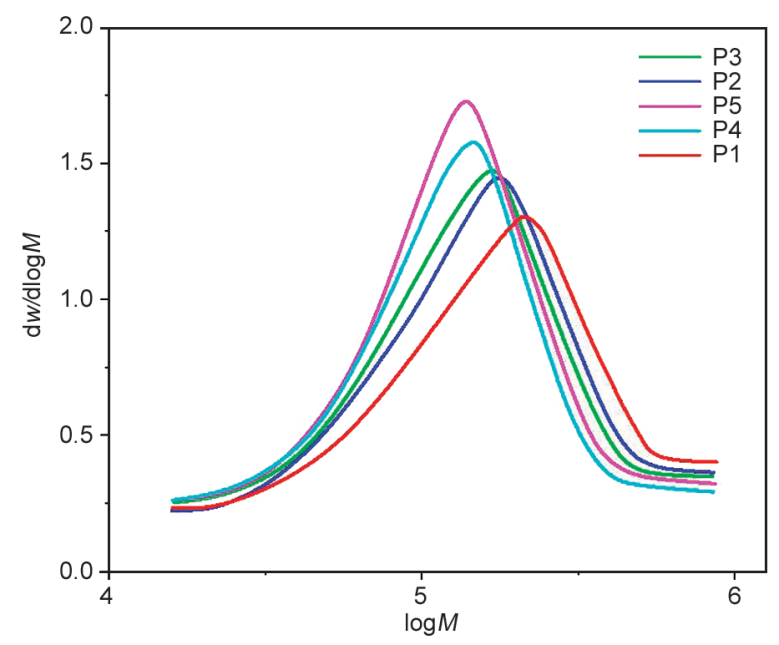

Figure 8. Gel permeation chromatography analysis of copolyesters P1-P5. weight-independent. The GPC analysis revealed that the weight-average molecular weight $\left(M_{\mathrm{w}}\right)$ of the samples ranged from 41400 to $48500 \mathrm{~g} / \mathrm{mol}$ (Table 1 ), and the polydispersity indices $(\nexists)$ were between 1.47 and 2.24. The polyesters were thus obtained with molecular weights satisfactory for most applications. The $M_{\mathrm{w}}$ of P1 was highest (48500 g/mol), possibly due to its amorphous character (no melting point observed) and the higher reactivity of ethylene glycol as compared with the longer chain diols. The relatively small variations in molecular weight observed among the copolyesters are likely the result of different reactivities of the diols towards the diesters, as all the diols used in the reactions had a chemical purity $>99 \%$.

In all cases, the molecular weight of the copolyesters was significantly higher than for furan-based copolyesters reported by Maniar et al. [28], with $M_{\mathrm{w}}$ of only $35000 \mathrm{~g} / \mathrm{mol}$, or for vanillin-based polyesters investigated by Zhao et al. [29], with $M_{\mathrm{w}}$ varying from 17000 to $40000 \mathrm{~g} / \mathrm{mol}$, indicating that thiophene monomers are more easily amenable to polyesters with high molecular weights.

\subsection{Thermal analysis}

The DSC curves obtained for the copolyesters are compared in Figure 9. The glass transition temperature of the samples varied between 47 and $120^{\circ} \mathrm{C}$, depending on the chain stiffness determined by the diol spacer length. Crystallization and melting peaks were observed for copolyesters P2, P3, and possibly for P4, but not for P1 nor P5. As compared with analogues derived from FDCA by Kasmi et al. [30], Knoop et al. [31], and Chebbi et al. [32], the polyesters synthesized in the current investigation have higher $T_{\mathrm{g}}$ values. For example, $T_{\mathrm{g}}$ values of $69.5,38$ and $20.6^{\circ} \mathrm{C}$ were reported for poly(vanillin-co-ethylene furanoate), poly(ethylene 2,5-furandicarboxylate-co-ethylene terephthalate) and poly(decamethylene- $c o$-isosorbide 2,5-furandicarboxylate), respectively, much lower than $T_{\mathrm{g}}=120^{\circ} \mathrm{C}$ measured for P1 in our work. The difference could lie in the larger bond angles for the more electronegative $\mathrm{O}$ atom as compared to $\mathrm{S}$, differences in electron mobility, and lower average electronic coupling for furan-based as compared to thiophene-based polyesters. The thiophene $\pi-\pi$ interactions are strikingly similar to furan, but higher non-local (hole)-phonon coupling is observed for thiophene than for furan, due to non-planarity of the thiophene ring [33]. Additionally, our results can be 


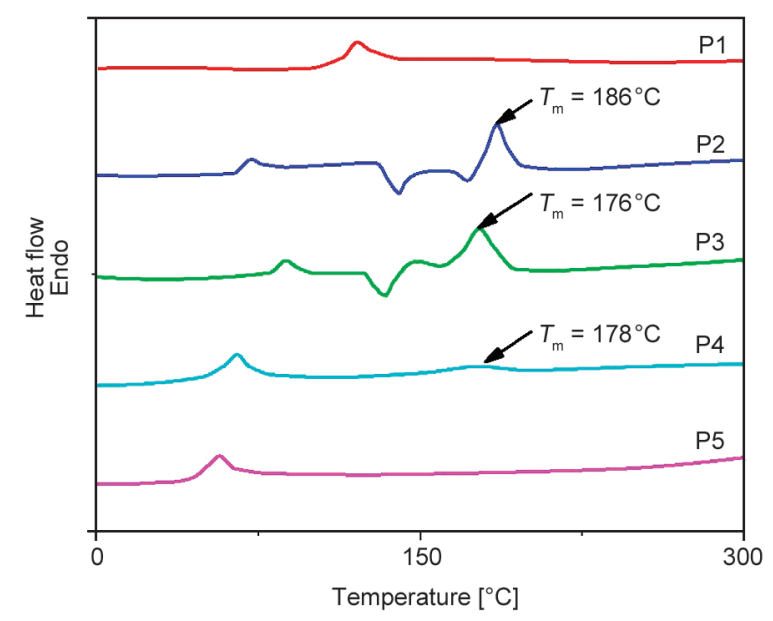

Figure 9. DSC curves for copolyesters P1-P5.

compared with vanillic acid-based polyesters, due to their structural similarity to TPA and their properties similar to PET. Two polyesters of interest, poly(ethylene vanillate) [34] and poly(propylene vanillate) [35], had $T_{\mathrm{g}}$ values of 83 and $68^{\circ} \mathrm{C}$, respectively, as compared with 120 and $72{ }^{\circ} \mathrm{C}$ for samples P1 and P2 synthesized in our work.

In Figure 10a, it is clear from the dTGA curve provided for P1 as an example that the polyesters followed a single-step thermal decomposition process, and in TGA (Figure 10b) all the copolyesters experienced a $5 \%$ weight loss $\left(T_{\mathrm{d}, 5 \%}\right)$ within a temperature range of $370-406^{\circ} \mathrm{C}$ under $\mathrm{N}_{2}$ atmosphere. Key parameters for thermal stability evaluation include the temperatures at which $5 \%\left(T_{\mathrm{d}, 5 \%}\right)$ and $50 \%\left(T_{\mathrm{d}, 1 / 2}\right)$ weight losses occur, the temperature at which the decomposition rate is maximum $\left(T_{\mathrm{d}, \max }\right)$, and the residual char at $600^{\circ} \mathrm{C}\left(R_{600}\right)$, as provided in Table 2 . The high decomposition temperatures observed are interesting because they provide a very broad processing window for these materials.

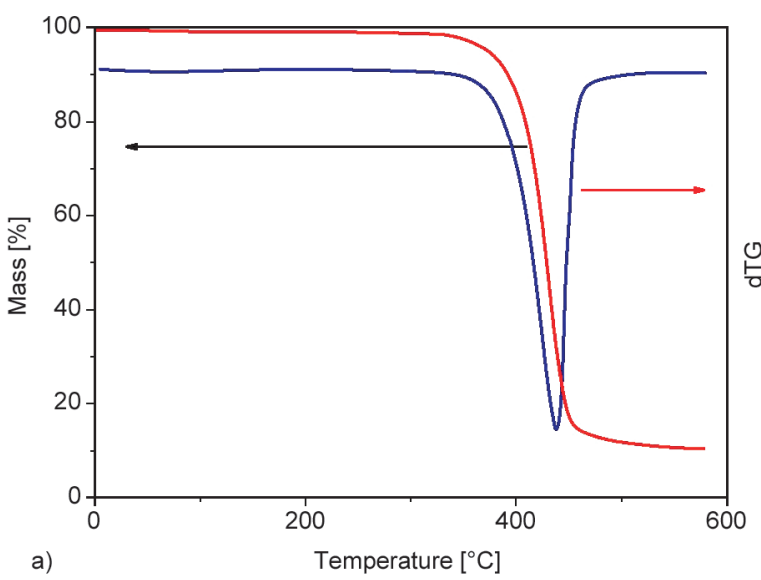

Table 2. Thermal properties of the copolyesters.

\begin{tabular}{|c|c|c|c|c|c|c|}
\hline Sample & $\begin{array}{c}\boldsymbol{T}_{\mathbf{d}, \mathbf{5} \%} \\
{\left[{ }^{\circ} \mathbf{C}\right]}\end{array}$ & $\begin{array}{c}\boldsymbol{T}_{\mathbf{d}, \max } \\
{\left[{ }^{\circ} \mathbf{C}\right]}\end{array}$ & $\begin{array}{c}\boldsymbol{T}_{\mathbf{d}, 1 / 2} \\
{\left[{ }^{\circ} \mathbf{C}\right]}\end{array}$ & $\begin{array}{c}\boldsymbol{T}_{\mathbf{m}} \\
{\left[{ }^{\circ} \mathbf{C}\right]}\end{array}$ & $\begin{array}{c}\boldsymbol{T}_{\mathbf{g}} \\
{\left[{ }^{\circ} \mathbf{C}\right]}\end{array}$ & $\begin{array}{c}\boldsymbol{R}_{\mathbf{6 0 0}} \\
{[\mathbf{w t} \mathbf{\%}]}\end{array}$ \\
\hline P1 & 406 & 425 & 421 & nd & 120 & 7.9 \\
\hline P2 & 390 & 418 & 418 & 186 & 72 & 3.8 \\
\hline P3 & 389 & 414 & 413 & 176 & 88 & 8.5 \\
\hline P4 & 380 & 406 & 408 & 178 & 56 & 5.9 \\
\hline P5 & 370 & 393 & 391 & nd & 47 & 4.7 \\
\hline
\end{tabular}

$\mathrm{nd}=$ could not be determined

A particular trend noticed for the copolyesters is that the 5\% decomposition temperature decreased slightly as number of carbon units in the aliphatic diols increased from the 1,2- to the 1,8-diol. As for the maximum decomposition temperature $\left(T_{\mathrm{d} \text { max }}\right)$, it also decreased from $425^{\circ} \mathrm{C}$ for $\mathrm{P} 1$ to $393^{\circ} \mathrm{C}$ for $\mathrm{P} 5$ under $\mathrm{N}_{2}$ atmosphere. The thermal stability of the copolyesters therefore decreased as the number of methylene units in the diols increased, and the residual char at $600{ }^{\circ} \mathrm{C}\left(R_{600}\right)$ also tended to decrease somewhat (Table 2). These results are comparable to the findings of Zamboulis et al. [34], when comparing the thermal stability of the petroleum-based analogues poly(ethylene terephthalate), poly(propylene terephthalate) and poly(butylene terephthalate), possessing $T_{\mathrm{d}, 5 \%}$ values in a range of $370-403^{\circ} \mathrm{C}$.

\subsection{Mechanical properties}

To determine the influence of the alkyl diol spacers on the mechanical properties of the copolyesters, dynamic mechanical and tensile testing were performed. The dynamic mechanical properties of the synthesized copolyesters are compared in Figure 11a. All the samples display two obvious transitions in the $0-200^{\circ} \mathrm{C}$ range. At most temperatures, the storage modulus follows the order $\mathrm{P} 1>\mathrm{P} 2>\mathrm{P} 3>\mathrm{P} 4>\mathrm{P} 5$,

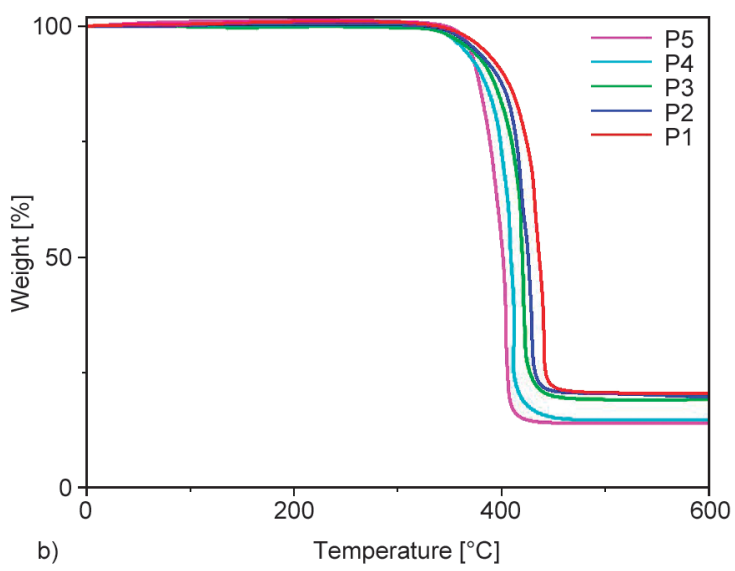

Figure 10. (a) Mass loss (TGA) and dTGA for P1; (b) TGA curves for copolyesters P1-P5 at $10^{\circ} \mathrm{C} / \mathrm{min}$ in $\mathrm{N}_{2}$. 

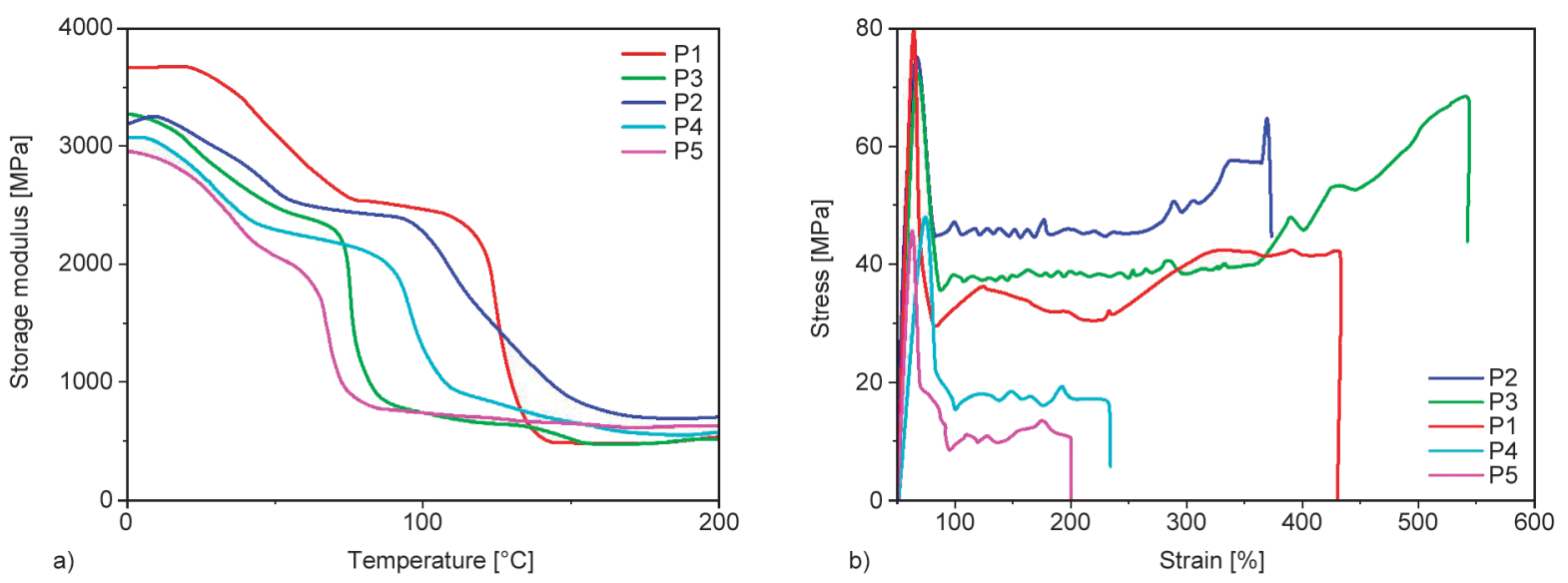

Figure 11. (a) Storage modulus and (b) tensile testing curves for copolyesters P1-P5.

attributed to the influence of the alkyl diol spacer length, and as temperature increases further, there exist a plateau region for the copolyesters beyond which further increase in temperature causes a large decrease in the storage modulus. These variations correlate with the $T_{\mathrm{g}}$ of the materials for amorphous samples P1 and P5, but are scrambled for samples P2-P4 due to the combined influence of crystallinity.

Wang et al. [22] measured a tensile strength of $56 \mathrm{MPa}$ and an elongation at break of $510 \%$ for PET. In Figure 11b, the tensile strength of copolyesters P1-P3 was 72-80, 16-24 MPa higher than for PET, with elongations at break of $390-540 \%$. These results are also much better than for poly(ethylene-co2,2,4,4-tetramethyl-1,3-cyclobutanediol 2,5-furandicarboxylate) (PETF) synthesized by Wang et al. [21], exhibiting a tensile strength of only $69 \mathrm{MPa}$ and an elongation at break of $270 \%$. The superior performance of the current samples is attributed to differences in crystallinity for polymers containing thiophene and aromatic rings, and to the length of the alkyl spacers, all of which contributed to the remarkable properties of the bio-based copolyesters.

These characteristics also caused a decrease in tensile strength, modulus, and/or melting point for samples $\mathrm{P} 4$ and $\mathrm{P} 5$, confirming the existence of a peak in performance for the $\mathrm{C}_{3}-\mathrm{C}_{4}$ diol alkyl spacers. The elongation at break of all the copolyesters synthesized was still in the range of 200-540\%, much higher than for furan-based polyesters (5-290\%) [36, 37], possibly due to differences in molecular weight and to the bond angles for the heteroatoms in the furan and thiophene rings of 148 and $129^{\circ}$, respectively, but also to the higher degree of aromaticity of the thiophene ring as compared with the furan ring [38,39]. When the alkyl spacer length in the diol increased to
Table 3. Mechanical properties copolyesters P1-P5 and selected reference samples.

\begin{tabular}{|l|c|c|c|}
\hline \multicolumn{1}{|c|}{ Sample } & $\begin{array}{c}\text { Tensile } \\
\text { modulus } \\
{[\mathbf{M P a}]}\end{array}$ & $\begin{array}{c}\text { Tensile } \\
\text { strength } \\
{[\mathbf{M P a}]}\end{array}$ & $\begin{array}{c}\text { Elongation at } \\
\text { break } \\
{[\%]}\end{array}$ \\
\hline PET [22] & $1170 \pm 40$ & $56 \pm 3$ & $508 \pm 90$ \\
\hline PETF [22] & $1430 \pm 20$ & $69 \pm 2$ & $270 \pm 10$ \\
\hline PDETH (P1) & $2700 \pm 10$ & $80 \pm 2$ & $440 \pm 30$ \\
\hline PDPTH (P2) & $2200 \pm 10$ & $73 \pm 2$ & $390 \pm 30$ \\
\hline PDBTH (P3) & $2350 \pm 10$ & $72 \pm 2$ & $540 \pm 30$ \\
\hline PDHTH (P4) & $2060 \pm 10$ & $48 \pm 2$ & $240 \pm 30$ \\
\hline PDOTH (P5) & $1890 \pm 10$ & $45 \pm 2$ & $200 \pm 30$ \\
\hline
\end{tabular}

$\mathrm{C}_{6}$ and $\mathrm{C}_{8}$, the tensile strength of $\mathrm{P} 4$ and $\mathrm{P} 5$ dropped to 48 and $45 \mathrm{MPa}$, and the elongation at break decreased to 240 and $200 \%$, respectively. This could be related to their lower $T_{\mathrm{g}}$ of only 56 and $47^{\circ} \mathrm{C}$, in addition to their poor crystallizability (Table 2 ). The tensile strength values observed at the yield and break points for P1, P2 and P3 are nevertheless comparable to high-density polyethylene (HDPE) [40] and polypropylene [41], whereas $\mathrm{P} 4$ and $\mathrm{P} 5$ are close to low-density polyethylene (LDPE) [42].

\subsection{Soil degradability of polyesters P1-P5}

A critical factor in the development of greener and eco-friendly polymeric materials lies in the ability of the materials to biodegrade in the environment after their life span is exceeded. In this investigation, a commercial PET sample and selected copolymers were subjected to soil degradation assays. The extent of biodegradation was quantified by recording the weight loss of the samples at predetermined time intervals. Biodegradation became significant after 15 weeks, but the degradation rate slowed down at longer times (Figure 12). The weight of the copolyesters decreased by $4.5-7.2 \%$ over the 


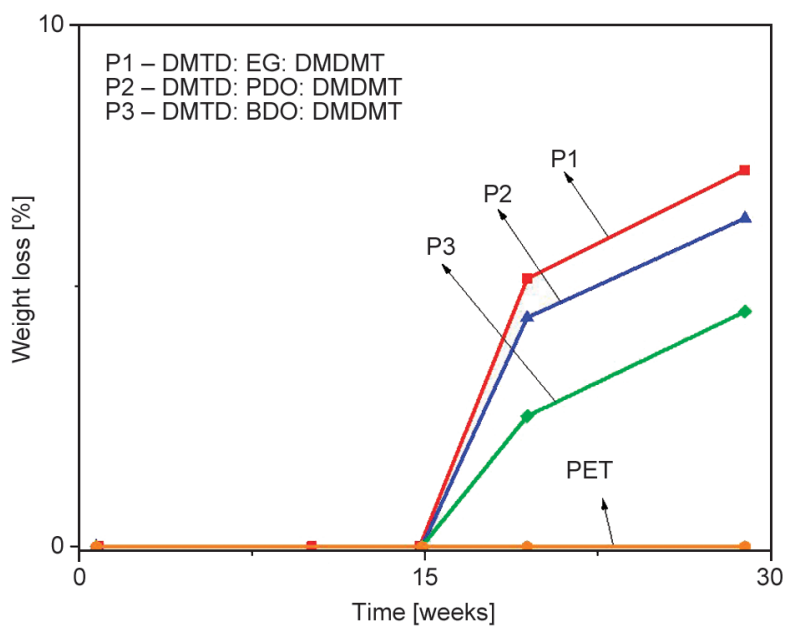

Figure 12. Biodegradation for copolyesters P1-P5.

28 week period of the investigation. In comparison, no apparent change was observed for commercial PET, confirming the poor degradability of that material.

An induction time at the beginning of the biodegradation processes has been observed for bio-based materials such as poly(lactic acid) and furan-based polyesters reported by Lyyra et al. [43] and Chebbi et al. [32], respectively, both in aqueous and controlled compost media. The explanation of this phenomenon lies in the nature of the hydrolytic chain scission process (combination of random and chainend scissions) occurring in the first step under the influence of enzymatic action. Initially, hydrolytic degradation occurring at the ester bonds within the macromolecular chains brings about random cleavage, resulting in the production of shorter chain segments and oligomers (micromolecular chains). As the phenomenon persists, the magnitude of the molecular weight reduces to threshold values allowing their easy solubilization and diffusion in the biodegradation medium [44]. Additionally, the $\mathrm{C}-\mathrm{S}$ bonds derived from dimethyl 2,5-thiophenedicarboxylate (DMTD) units is an added advantage for degradation, since sulfur serves as substrate for microorganisms (sulfur-loving bacteria), thereby promoting hydrolytic degradation. The weight losses were still lower than for furan-based polyesters reported by Lyrra et al. [43] (maximum weight loss of $12.5 \%$, as compared with $7.2 \%$ in the current investigation), mainly due to the higher electronegativity of $\mathrm{O}$ as compared with $\mathrm{S}$, and also due to the insertion of small amounts of isosorbide in the backbone. Since isosorbide is a sugar-derived diol of biological origin, it is easily digestible by microorganisms in the soil, thereby contributing to increased degradability [15]. Another feature observed in the plots is that the weight loss tends to increase for decreasing alkyl diol spacer lengths in the polyester backbone. From the biodegradation test results, it is understood that the rate of biodegradation decreases as the number of methylene units in the diol spacer increases, therefore copolyester P1 was more strongly degraded than $\mathrm{P} 2$ and $\mathrm{P} 3$. The main distinguishing feature of P1 is its amorphous character, which likely contributed to its higher degradation rate due to enhanced accessibility of the ester bonds to the depolymerizing microorganisms [45]. In addition, it is well known that amorphous regions of semi-crystalline polymers are more prone to degradation than the well-ordered and more densely packed crystalline ones. Differences in crystallinity and chemical reactivity may therefore explain the observed trends. Indeed, similar findings were reported for certain starch-based bioplastics and isosorbide-furan based polyesters, which began to decompose after a certain time due to crystallinity [46-48].

Irrespective of the results obtained, a better way to degrade these polymers would likely be enzymatic catalysis since their degradation efficiency may be similar to poly(ethylene furanoate), and the resulting monomers could be recovered and reused for the synthesis of polyesters rather than 'lost' in the ground. This method has proven to be more efficient (selective) when specific enzymes are used, as described in recent investigations of Weinberger and coworkers $[49,50]$.

\section{Conclusions}

Fully bio-based random thiophene-aromatic polyesters were synthesized from dimethyl 2,5-thiophenedicarboxylate (DMTD), dimethyl 2,5-dimethoxyterephthalate (DMDMT) and aliphatic diols via an environmentally sustainable catalytic method. In all cases, the weight-average molecular weight was over $40000 \mathrm{~g} / \mathrm{mol}$ and the polydispersity indices varied between 1.47 and 2.24. DSC analysis revealed that copolymers $\mathrm{P} 2, \mathrm{P} 3$, and possibly $\mathrm{P} 4$ were semicrystalline, while no clear melting nor crystallization peaks were observed for P1 and P5. The degree of flexibility (or rigidity) present in the polymer chains is obviously related to the length of the alkyl spacer in the diol units. Tensile testing showed that all the 
polyesters exhibited good toughness (elongation at break of $200-540 \%$ ). Remarkable degradability reaching 7.2, 6.3 and $4.5 \%$ after 28 weeks were observed for P1, P2 and P3, respectively, much higher than for commercial PET, despite their high $T_{\mathrm{g}}$. In summary, the copolymers synthesized in this work possess many outstanding features of interest for practical applications including sustainability, good thermal stability, tunable mechanical properties, and biodegradability, such that they should be suitable to replace petroleum-based commercial PET in the food packaging industry, which is helpful for the polymer industry to implement carbon neutrality and contribute to sustainable development.

\section{Acknowledgements}

The authors acknowledge the financial support from Program (BG20190227001) of High-end Foreign Experts of The State Administration of Foreign Experts Affairs (SAFEA). The financial support from Program (BG20190227001) of Highend Foreign Experts of The State Administration of Foreign Experts Affairs (SAFEA).

\section{References}

[1] Gandini A., Lacerda T. M.: From monomers to polymers from renewable resources: Recent advances. Progress in Polymer Science, 48, 1-39 (2015). https://doi.org/10.1016/j.progpolymsci.2014.11.002

[2] Saviello D., Cespi D., Sharma V., Miao S., Cucciniello R.: The frontier of biobased polymers: Synthesis, characterization, application, and sustainability assessment. International Journal of Polymer Science, 2017, 5638598 (2017). https://doi.org/10.1155/2017/5638598

[3] Editorial: The future of plastic. Nature Communications, 9, 2157 (2018). https://doi.org/10.1038/s41467-018-04565-2

[4] Zia K. M., Noreen A., Zuber M., Tabasum S., Mujahid M.: Recent developments and future prospects on biobased polyesters derived from renewable resources: A review. International Journal of Biological Macromolecules, 82, 1028-1040 (2016).

https://doi.org/10.1016/j.ijbiomac.2015.10.040

[5] Stoclet G., Lefebvre J. M., Yeniad B., Gobius du Sart G., de Vos S.: On the strain-induced structural evolution of poly(ethylene-2,5-furanoate) upon uniaxial stretching: An in-situ SAXS-WAXS study. Polymer, 134, 227241 (2018).

https://doi.org/10.1016/j.polymer.2017.11.071

[6] Rosenboom J-G., Hohl D. K., Fleckenstein P., Storti G., Morbidelli M.: Bottle-grade polyethylene furanoate from ring-opening polymerisation of cyclic oligomers. Nature Communications, 9, 2701 (2018). https://doi.org/10.1038/s41467-018-05147-y
[7] Zhu J., Cai J., Xie W., Chen P-H., Gazzano M., Scandola M., Gross R. A.: Poly(butylene 2,5-furan dicarboxylate), a biobased alternative to PBT: Synthesis, physical properties, and crystal structure. Macromolecules, 46, 796-804 (2013).

https://doi.org/10.1021/ma3023298

[8] Papageorgiou G. Z., Tsanaktsis V., Papageorgiou D. G., Exarhopoulos S., Papageorgiou M., Bikiaris D. N.: Evaluation of polyesters from renewable resources as alternatives to the current fossil-based polymers. Phase transitions of poly(butylene 2,5-furan-dicarboxylate). Polymer, 55, 3846-3858 (2014).

https://doi.org/10.1016/j.polymer.2014.06.025

[9] Zhang J-B., Zhang H., Jin F-L., Park S-J.: Enhancement of impact strength of poly(lactic acid)/silicon carbide nanocomposites through surface modification with titanate-coupling agents. Bulletin of Materials Science, 43, 6 (2020). https://doi.org/10.1007/s12034-019-1977-z

[10] Luo Y., Lin Z., Guo G.: Biodegradation assessment of poly (lactic acid) filled with functionalized titania nanoparticles $\left(\mathrm{PLA} / \mathrm{TiO}_{2}\right)$ under compost conditions. Nanoscale Research Letters, 14, 56 (2019).

https://doi.org/10.1186/s11671-019-2891-4

[11] Wang G., Jiang M., Zhang Q., Wang R., Liang Q., Zhou G.: New bio-based copolyesters derived from 1,4-butanediol, terephthalic acid and 2,5-thiophenedicarboxylic acid: Synthesis, crystallization behavior, thermal and mechanical properties. Polymer Testing, 75, 213-219 (2019).

https://doi.org/10.1016/j.polymertesting.2019.02.020

[12] Gigli M., Quartinello F., Soccio M., Pellis A., Lotti N., Guebitz G. M., Munari A.: Enzymatic hydrolysis of poly (1,4-butylene 2,5-thiophenedicarboxylate) (PBTF) and poly(1,4-butylene 2,5-furandicarboxylate) (PBF) films: A comparison of mechanisms. Environment International, 130, 104852 (2019).

https://doi.org/10.1016/j.envint.2019.05.046

[13] Kim H. J., Reddi Y., Cramer C. J., Hillmyer M. A., Ellison C. J.: Readily degradable aromatic polyesters from salicylic acid. ACS Macro Letters, 9, 96-102 (2020).

https://doi.org/10.1021/acsmacrolett.9b00890

[14] Müller R-J., Kleeberg I., Deckwer W-D.: Biodegradation of polyesters containing aromatic constituents. Journal of Biotechnology, 86, 87-95 (2001). https://doi.org/10.1016/S0168-1656(00)00407-7

[15] Terzopoulou Z., Papadopoulos L., Zamboulis A., Papageorgiou D. G., Papageorgiou G. Z., Bikiaris D. N.: Tuning the properties of furandicarboxylic acid-based polyesters with copolymerization: A review. Polymers, 12, 1209 (2020). https://doi.org/10.3390/polym12061209

[16] Wang J-G., Liu X-Q., Zhu J.: From furan to high quality bio-based poly(ethylene furandicarboxylate). Chinese Journal of Polymer Science, 36, 720-727 (2018). https://doi.org/10.1007/s10118-018-2092-0 
[17] Wang G., Jiang M., Zhang Q., Wang R., Liang Q., Zhou G.: New bio-based copolyesters poly(trimethylene 2,5thiophenedicarboxylate-co-trimethylene terephthalate): Synthesis, crystallization behavior, thermal and mechanical properties. Polymer, 173, 27-33 (2019). https://doi.org/10.1016/j.polymer.2019.04.024

[18] Desrosiers N., Bergeron J-Y., Belletête M., Durocher G., Leclerc M.: Synthesis and characterization of novel aromatic polyesters derived from thiophenes. Polymer, 37, 675-680 (1996).

https://doi.org/10.1016/0032-3861(96)83155-7

[19] Fijten M. W. M., Kranenburg J. M., Thijs H. M. L., Paulus R. M., van Lankvelt B. M., de Hullu J., Springintveld M., Thielen D. J. G., Tweedie C. A., Hoogenboom R., van Vliet K. J., Schubert U. S.: Synthesis and structure-property relationships of random and block copolymers: A direct comparison for copoly (2-oxazoline)s. Macromolecules, 40, 5879-5886 (2007). https://doi.org/10.1021/ma070720r

[20] Xu J., Wang Y., Chung T-S., Goh S. H.: Aromatic liquid-crystalline polyesters comprising a 2,5-thiophene unit synthesized and studied by the thin-film polymerization method. Journal of Materials Research, 18, 15091521 (2003).

https://doi.org/10.1557/JMR.2003.0209

[21] Wang G., Yang G., Jiang M., Wang R., Liang Y., Zhou G.: Poly(propylene naphthalate-co-propylene 2,5-thiophenedicarboxylate)s derived from bio-based 2,5-thiophenedicarboxylic acid (TDCA): Synthesis and properties. Polymer Testing, 93, 106955 (2020).

https://doi.org/10.1016/j.polymertesting.2020.106955

[22] Wang J-G., Zhang X-Q., Shen A., Zhu J., Song P-A., Wang H., Liu X-Q.: Synthesis and properties investigation of thiophene-aromatic polyesters: Potential alternatives for the 2,5-furandicarboxylic acid-based ones. Chinese Journal of Polymer Science, 38, 10821091 (2020). https://doi.org/10.1007/s10118-020-2438-2

[23] Wang G., Liang Y., Jiang M., Zhang Q., Wang R., Wang H., Zhou G.: High $T_{\mathrm{g}}$ and tough poly(butylene 2,5-thiophenedicarboxylate-co-1,4-cyclohexanedimethylene 2,5-thiophenedicarboxylate)s: Synthesis and characterization. Journal of Applied Polymer Science, 137, 48634 (2019).

https://doi.org/10.1002/app.48634

[24] Wang G., Liang Y., Jiang M., Zhang Q., Wang R., Wang H., Zhou G.: Synthesis and characterization of biobased polyesters from 2,5-thiophenedicarboxylic acid. Polymer Degradation and Stability, 168, 108942 (2019). https://doi.org/10.1016/j.polymdegradstab.2019.108942

[25] Wu S., Zhang Y., Han J., Xie Z., Xu J., Guo B.: Copolymerization with polyether segments improves the mechanical properties of biodegradable polyesters. ACS Omega, 2, 2639-2648 (2017).

https://doi.org/10.1021/acsomega.7b00517
[26] Queiroz M-J., Joseph D., Kirsch G.: Improved preparation of 2,5-dimethyl-1,4-cyclohexanedione. Organic Preparations and Procedures International, 27, 120-122 (1995). https://doi.org/10.1080/00304949509458191

[27] Ogunjobi J. K., Farmer T. J., McElroy C. R., Breeden S. W., Macquarrie D. J., Thornthwaite D., Clark J. H.: Synthesis of biobased diethyl terephthalate via DielsAlder addition of ethylene to 2,5-furandicarboxylic acid diethyl ester: An alternative route to $100 \%$ biobased poly(ethylene terephthalate). ACS Sustainable Chemistry and Engineering, 7, 8183-8194 (2019).

https://doi.org/10.1021/acssuschemeng.8b06196

[28] Maniar D., Jiang Y., Woortman A. J. J., van Dijken J., Loos K.: Furan-based copolyesters from renewable resources: Enzymatic synthesis and properties. ChemSusChem, 12, 956-990 (2019).

https://doi.org/10.1002/cssc.201802867

[29] Zhao C., Huang C., Chen Q., Ingram I. D. V., Zeng X., Ren T., Xie H.: Sustainable aromatic aliphatic polyesters and polyurethanes prepared from vanillin-derived diols via green catalysis. Polymers, 12, 586 (2020). https://doi.org/10.3390/polym12030586

[30] Kasmi N., Papadopoulos L., Chebbi Y., Papageorgiou G. Z., Bikiaris D. N.: Effective and facile solvent-free synthesis route to novel biobased monomers from vanillic acid: Structure-thermal property relationships of sustainable polyesters. Polymer Degradation and Stability, 181, 109315 (2020).

https://doi.org/10.1016/j.polymdegradstab.2020.109315

[31] Knoop R. J. I., Vogelzang W., van Haveren J., van Es D. S.: High molecular weight poly(ethylene-2,5-furanoate); Critical aspects in synthesis and mechanical property determination. Journal of Polymer Science Part A: Polymer Chemistry, 51, 4191-4199 (2013).

https://doi.org/10.1002/pola.26833

[32] Chebbi Y., Kasmi N., Majdoub M., Cerruti P., Scarinzi G., Malinconico M., Pogetto G. D., Papageorgiou G. Z., Bikiaris D. N.: Synthesis, characterization, and biodegradability of novel fully biobased poly(decamethylene-co-isosorbide 2,5-furandicarboxylate) copolyesters with enhanced mechanical properties. ACS Sustainable Chemistry and Engineering, 7, 5501-5514 (2019). https://doi.org/10.1021/acssuschemeng.8b06796

[33] Turan H. T., Yavuz İ., Aviyente V.: Understanding the impact of thiophene/furan substitution on intrinsic charge-carrier mobility. The Journal of Physical Chemistry C, 121, 25682-25690 (2017).

https://doi.org/10.1021/acs.jpcc.7b07477

[34] Zamboulis A., Papadopoulos L., Terzopoulou Z., Bikiaris D. N., Patsiaoura D., Chrissafis K., Gazzano M., Lotti N., Papageorgiou G. Z.: Synthesis, thermal properties and decomposition mechanism of poly(ethylene vanillate) polyester. Polymers, 11, 1672 (2019). https://doi.org/10.3390/polym11101672 
[35] Xanthopoulou E., Terzopoulou Z., Zamboulis A., Papadopoulos L., Tsongas K., Tzetzis D., Papageorgiou G. Z., Bikiaris D. N.: Poly(propylene vanillate): A sustainable lignin-based semi-crystalline engineering polyester. ACS Sustainable Chemistry and Engineering, 9, 1383-1397 (2021).

https://doi.org/10.1021/acssuschemeng.0c08346

[36] Zhang J., Liu Y., Qi Z., He L., Peng L.: Progress in the synthesis and properties of 2,5-furan dicarboxylate based polyesters. BioResources, 15, 4502-4527 (2020). https://doi.org/10.15376/biores.15.2.Zhang

[37] Guidotti G., Soccio M., Lotti N., Gazzano M., Siracusa V., Munari A.: Poly(propylene 2,5-thiophenedicarboxylate) vs. poly(propylene 2,5-furandicarboxylate): Two examples of high gas barrier bio-based polyesters. Polymers, 10, 785 (2018).

https://doi.org/10.3390/polym10070785

[38] Zakrzewska M. E., Bogel-Łukasik E., Bogel-Łukasik R.: Ionic liquid-mediated formation of 5-hydroxymethylfurfural - A promising biomass-derived building block. Chemical Reviews, 111, 397-417 (2011).

https://doi.org/10.1021/cr100171a

[39] Wang J., Sun L., Shen Z., Zhu J., Song X., Liu X.: Effects of various 1,3-propanediols on the properties of poly(propylene furandicarboxylate). ACS Sustainable Chemistry and Engineering, 7, 3282-3291 (2019). https://doi.org/10.1021/acssuschemeng.8b05288

[40] Madhu G., Bhunia H., Bajpai P. K., Chaudhary V.: Mechanical and morphological properties of high density polyethylene and polylactide blends. Journal of Polymer Engineering, 34, 813-821 (2014). https://doi.org/10.1515/polyeng-2013-0174

[41] Graziano A., Jaffer S., Sain M.: Review on modification strategies of polyethylene/polypropylene immiscible thermoplastic polymer blends for enhancing their mechanical behavior. Journal of Elastomers and Plastics, 51, 291-336 (2018). https://doi.org/10.1177/0095244318783806

[42] Sahraeian R., Esfandeh M.: Mechanical and morphological properties of LDPE/perlite nanocomposite films. Polymer Bulletin, 74, 1327-1341 (2016) https://doi.org/10.1007/s00289-016-1779-Z
[43] Lyyra I., Leino K., Hukka T., Hannula M., Kellomäki M., Massera J.: Impact of glass composition on hydrolytic degradation of polylactide/bioactive glass composites. Materials, 14, 667 (2021).

https://doi.org/10.3390/ma14030667

[44] Funabashi M., Ninomiya F., Kunioka M.: Biodegradability evaluation of polymers by ISO 14855-2. International Journal of Molecular Science, 10, 3635-3654 (2009). https://doi.org/10.3390/ijms10083635

[45] Gorrasi G., Pantani R.: Hydrolysis and biodegradation of poly(lactic acid). in 'Synthesis, structure and properties of poly(lactic acid)' (eds.: Di Lorenzo M., Androsch R.) Advances in Polymer Science, Springer, Cham, Vol 279, 119-151 (2017).

https://doi.org/10.1007/12 2016 12

[46] Guidotti G., Gigli M., Soccio M., Lotti N., Salatelli E., Gazzano M., Siracusa V., Munari A.: Tailoring poly (butylene 2,5-thiophenedicarboxylate) features by the introduction of adipic acid co-units: Biobased and biodegradable aliphatic/aromatic polyesters. Polymer, 145, 11-20 (2018). https://doi.org/10.1016/j.polymer.2018.04.063

[47] Min K., Cuiffi J. D., Mathers R. T.: Ranking environmental degradation trends of plastic marine debris based on physical properties and molecular structure. Nature Communications, 11, 727 (2020). https://doi.org/10.1038/s41467-020-14538-Z

[48] Zumstein M. T., Schintlmeister A., Nelson T. F., Baumgartner R., Woebken D., Wagner M., Kohler H-P., Mcneill K., Sander M.: Biodegradation of synthetic polymers in soils: Tracking carbon into $\mathrm{CO}_{2}$ and microbial biomass. Science Advances, 4, eaas9024 (2018). https://doi.org/10.1126/sciadv.aas9024

[49] Weinberger S., Haernvall K., Scaini D., Ghazaryan G., Zumstein M. T., Sander M., Pellis A., Guebitz G. M.: Enzymatic surface hydrolysis of poly(ethylene furanoate) thin films of various crystallinities. Green Chemistry, 19, 5381-5384 (2017).

https://doi.org/10.1039/C7GC02905E

[50] Weinberger S., Canadell J., Quartinello F., Yeniad B., Arias A., Pellis A., Guebitz G. M.: Enzymatic degradation of poly(ethylene 2,5-furanoate) powders and amorphous films. Catalysts, 7, 318 (2017).

https://doi.org/10.3390/catal7110318 